\title{
What makes you move? A minimalist study of object displacement in English Double Object Construction
}

\author{
Aleksandra Bartczak-Meszyńska \\ University of Finance and Management, Białystok, Poland
}

\begin{abstract}
The aim of this paper is to analyse the displacement phenomena the direct and indirect objects in the English Double Object Construction (DOC) can undergo. The focus is on the movement out of the DOC to the sentence initial position. The analysis concerns not only globally acceptable Goal-Theme object sequence but also the Theme-Goal DOC, which grammaticality is restricted only to a few British English dialects. The processes affecting the objects in the Prepositional Construction are also mentioned. The initial part of the paper is devoted to the underlying syntactic representations of the DOC in English. Following, e.g. Citko (2011), Cuervo (2003), Pylkkännen (2002, 2008), a representation with the Low Applicative Phrase has been adopted. The exact case valuation mechanism for relevant objects (as proposed by Bondaruk and Bartczak-Meszyńska (2014)) has been established. The remaining part of this paper contains a detailed discussion of the derivation of particular object initial sentences with the DOC in the active and in the passive and the interplay between passivisation and topicalisation, as the triggers of the object fronting.
\end{abstract}

Keywords: Double Object Construction, passivisation, topicalisation, the Minimalist Program, the Low Applicative Phrase

\section{Introduction}

The aim of this paper is to analyse object displacement phenomena affecting Direct (DO) and Indirect objects (IO) in the Double Object Construction (DOC) in English. We concentrate on the triggers and nature of movement either object can undergo from within the DOC to the sentence initial position. Subject to this study are not only cases where both objects are realised by nominal expressions, such as DPs or pronouns but also instances of Prepositional Construction (PC), where a PP functions as one of the objects, both in the active and the passive. This analysis is carried out in the framework of the Minimalist Program proposed by Chomsky (2000, 2001, 2007, 2008). Our investigation utilizes the syntactic representations of English DOC with the Applicative Phrase, as proposed by e.g. Pylkkännen (2008) for Greek and employs a case valuation mechanism put forward by Bartczak-Meszyńska (2013) and Bondaruk and Bartczak-Meszyńska (2014). 
This paper consists of 5 sections. Section one is the introduction. Section two contains a presentation of the relevant data and a brief introduction to the properties of the DOC in English. Section three discusses the underlying syntactic structures of the DOC and PC in English, together with the precise mechanism of case valuation in the active and in the passive. Section four offers a detailed analysis of the triggers and nature of object fronting in DOCs and PCs, i.e. what causes the movement and how it proceeds. Section five concludes the paper.

\section{The properties of English DOC}

Before we proceed with the actual discussion of the instances of the DOC acceptable in English, one remark concerning the sequence of objects is in order. In languages with rich inflectional systems, the status of each object can be recognized by its inflectional affix- the IO is usually marked with the dative case and functions most often as a Recipient or Benefactor, the case of the DO is valued as the accusative and the DO usually represents a Theme. ${ }^{1}$ Initially, Old English (OE) was this kind of language but it gradually changed. First the case syncretism occurred (the same ending began to denote two or more cases, e.g. the dative and the accusative or the dative and the genitive), then the inflectional case marking disappeared altogether. ${ }^{2}$ This process started in late Old English and resulted in establishing the IO-DO word order, when both objects were DPs, or so-called Prepositional Dative, with the nominal DO followed by an IO realised by a PP headed by to. ${ }^{3}$

In contemporary English the acceptability of the DOC patterns varies among dialects: American English and certain British English allow only IO-DO DOC. The speakers of some British dialects find also the DO-IO sequence equally acceptable. In this analysis we concentrate on the DOC structures available in the British English dialects, which allow objects to occur in both sequences.

\subsection{The data}

The examples in (1) illustrate all the DOC patterns possible in English in the active. The acceptability of this word order is closely related to the part of speech both objects get realised by. The DO-IO sequence seems to be the most difficult for native speakers to accept when DPs surface as both objects as in (1c). We are going to support our analysis with an in-depth study of this aspect of British English, based on the judgments of native speakers of different dialects, from different backgrounds and with different levels of education, carried out by Haddican (2010). He claims that (1c) is considered grammatical in the variety of English spoken in the Manchester area, Hughes and Trudgill (1979:21) list similar sentences as grammatical as well. The grammaticality of examples increases when the DO is a pronoun and

\footnotetext{
1 The study here focuses on the nominative-accusative languages, the observations concerning cases can be different for the languages with ergative-absolutive case systems. For more details concerning the theta roles of objects see Levin and Rappaport Hovav (2007).

2 The remaining inflectional forms are still visible in the pronoun system in English.

3 A detailed characteristics of this process is presented in McFadden (2002).
} 
the IO a DP, as in (1d) and (1e). Generally, the speakers of English are more willing to consider the DO-IO DOC grammatical, when weak phonetic elements appear as both objects, such as pronouns (as in (1f)) or reduced pronouns (as in (1g)). ${ }^{4}$

(1) a. The man gave the boy a pen.

b. The man gave the pen to the boy.

?c. The man gave the pen the boy. ${ }^{5}$

$\% \mathrm{~d}$. The man gave the pen him.

$\%$ e. The man gave it the boy.

f. The man gave it him.

g. The man gave it 'im.

The sentences in (2) illustrate the formation of passive sentences with the English DOC. We need to emphasise here the fact that although certain speakers accept the DO-IO object order does not entail that the DO passivisation is attested in their idiolect. On the other hand, the speakers allowing the DO passivisation always perceive the $\mathrm{DO}-\mathrm{IO}$ sequence as grammatical.

(2) a. The pen was given to the boy.

b. The boy was given the pen.

$\%$ c. The pen was given the boy.

$\% \mathrm{~d}$. The pen was given him/'im.

As the examples in (2) illustrate, either the DO or the IO can become the subject of a passive sentence in English. However, when the DO becomes a passive sentence subject, the majority of English speakers exhibit preference for the IO to surface as a PP headed by to, as in (2a). The most controversial is example in $(2 \mathrm{c})$, where the DO becomes the subject in the passive and the IO is realised by a DP. The controversy is diminished in $(2 \mathrm{~d})$ when a phonetically weak element functions as an IO.

In English, either object can occur sentence initially both in the active (as in (3)) and in the passive (as in (4)). However, they are not neutral utterances and are only acceptable in particular discourse situations.

(3) a. The pen, the man gave to the boy/him.

b. To the boy/To him, the man gave the pen.

$\%$ c. The boy/Him, the man gave the pen.

d. The pen, the man gave the boy/him.

(4) a. The pen, the boy/he was given.

$\%$ b. The boy/him, the pen was given.

c. To the boy/him, the pen was given.

4 All the exemplary sentences are provided by the author and modeled on the examples in the literature, unless otherwise stated.

5 Following symbols have been used with the data: '?' denotes the sentences with questionable grammaticality whereas '\%' signals structures which are found acceptable by some percentage of the speakers of a given language. 
In the examples above with the sentence initial objects, no matter whether in the active (in (3)) or in the passive (in (4)), the fronted object is evidently emphasised. Such a sentence would not be used as an answer to a fairly neutral question What did the boy get for his birthday? assuming a relatively low familiarity with the situation but it would rather answer the question Did the boy get a pen or a book? indicating a greater knowledge of the discourse context.

\subsection{Alternative Projection}

The term Alternative Projection has been introduced by Larson (1990) to characterise the suggestion that the DOC and the PC instantiate two different underlying structures, since they exhibit semantic and syntactic properties too different to be connected via transformations. ${ }^{6}$ Why is it necessary to discuss the issue of an Alternative Projection here? Two questions connected with this phenomenon can be raised, one whether the DO-IO DOC in English exemplifies a 'true' DOC or whether this structure is derived from a PC by the loss of the preposition (either to or for). The other question concerns the issue whether the DOC and the PC are derivationally related to each other.

The answer to the former question is provided by Haddican (2010), Holmberg and Haddican (2011), Biggs $(2014,2015)$, among others, who analyse the DO-IO DOC in English. Haddican (2010) underlines the structural and transformational similarities between the DOIO and the IO-DO structures (e.g. allowing or not nominalisations to be built or inducing or not Person Case Constraint effects) as well as the discrepancies between the PC and both types of DOC (IO-DO and DO-IO DOC exhibit properties different from the PC). ${ }^{7}$ Moreover, Bruening (2010a), following a number of papers by Bresnan (2007), Bresnan, et. al. (2007), Bresnan and Nikitina (2009), among others, claims that not all occurrences of PC are true PCs but in fact instantiate DOCs with a reversed order, especially when the IO is realized by a prosodically heavy element, like a sentence.

The supporters of the Alternative Projection account for the structures of the DOC and the PC either in an asymmetric way with two separate underlying representations, e.g. the DOC with the Applicative Phrase (e.g. Anagnostopoulou (2003), Cuervo (2003), Pylkännen (2008)) and the canonical representation of the PC with a PP or they propose symmetric structures with an empty prepositional projection in the DOC. The symmetric approach can be found in Harley (2002), who suggests a representation of ditransitive verbs with two projections, constituting small clauses. In the DOC, the CAUSE predicate ( $\mathrm{v}_{\mathrm{CAUSE}}$ ) selects an External Argument (EA, the subject) and a prepositional component $\mathrm{P}_{\mathrm{HAVE}}$, whereas in the PC

\footnotetext{
6 The modern discussion of the structure of the DOC and the presence and function of prepositions in it was initiated by Emonds (1973), Oehrle (1976), and culminated in the polemic between Larson $(1988,1990)$ and Jackendoff (1990).

7 However, as pointed out by an anonymous reviewer, this is not always the case, since Liverpool indirect passive is actually derived from the Prepositional Dative and is not related to the DOC, as discussed by Biggs (2015).
} 
the PP is headed not by to but an abstract locative Preposition $\mathrm{P}_{\mathrm{LOC}}{ }^{8}$ However, Bruening (2010b) criticises attempts to account for the structures of the DOC and the PC in a symmetric manner and provides arguments against the presence of small clauses in either structure or considering the PP to be a small clause.

\section{The syntactic structure of the DOC in English and case valuation}

\subsection{The structure of the DOC in English}

The structure of the DOC proposed in this paper contains the Applicative Phrase. The discussion concerning the syntactic structure of this construction in English excluded the presence of High Applicatives in English (e.g. Boneh and Nash (2011), Cuervo (2003), Pylkkänen (2008), Slavkov (2008), Grashchenkov and Markman (2008)). ${ }^{9}$ Since our aim here is to propose a structure of the English DOC which allows us to account for the fronting of objects and the passivisation of either object, we adapt a relatively straightforward proposal made for the Polish DOC by Citko (2011) for the English DOC. ${ }^{10}$ The structure of the English DOC is depicted in (5) below:

(5)

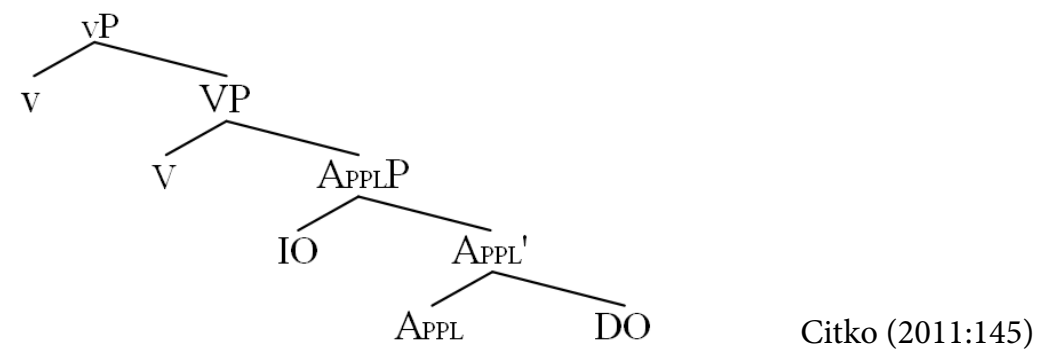

This structure might seem a little problematic, especially since the DO is situated further away from the phase head and this could lead to locality violations - any syntactic operation from the phase head targeting the DO would have to cross the IO. However, if combined with additional assumptions concerning case valuation, this structure proves to be an efficient tool to account for object dislocation and passivization possibilities in the English DOC. In order to prove that, let us now turn to the issue of case valuation in English.

8 Actually, Harley (2002) bases her proposal on Pesetsky's (1995) representation of the DOC, with a PP headed by an empty Preposition G with modifications suggested by Kayne (1994).

9 The Applicative Phrase has been proposed by Pylkkänen (2002), published as Pylkkännen (2008). She claims that if the Applicative is merged below the verb, it instantiates the Low Applicative, if it merges above the verb then it is the High Applicative. Cuervo (2003) further modifies this classification adding the Affected Applicative, a particular form of the High Applicative, present in languages like Spanish or German.

${ }^{10}$ Other proposals concerning the structure of the DOC in English have been made, e.g., Haddican and Holmberg (2011) with a linking element (a Linker) or Grashchenkov and Markman (2008) with applicativised verbs in addition to the Applicatives. 


\subsection{The mechanism of case valuation in the English DOC}

The issue of case valuation is quite complicated in English, as the inflectional marking has been lost, hence the case of nominal expressions must be determined in some other way. Bartczak-Meszyńska (2013) and Bondaruk and Bartczak-Meszyńska (2014) attempt to determine the cases of objects in Modern English (ME) by the diachronic analysis of the English case system and a comparison of English data with the contemporary German DOC.

In Old English, each nominal expression, whether a DP or a pronoun, was clearly marked for case by means of inflectional endings. Therefore, it is not surprising that the word order in OE was relatively free and both IO-DO and DO-IO sequences were attested, as the theta role of each object could have been identified by its case. Moreover, object initial sentences occurred significantly frequently and were not as stylistically marked as they are today, as illustrated in (6) below.

(6) Dem acennendan Cynige we bringað gold. Stor we him bringap, gif... the born king ${ }_{\mathrm{DAT}}$ we bring gold incense we him bring, if... 'To the born king we bring gold. We bring him incense, if...'

Homilies of Ælfric I, I 7.118.4

The ways of expressing the passive in Old English also differ significantly from ME. In OE, the structure called impersonal passive, no longer acceptable, was attested. This structure consisted of a dative or genitive object with a verb in third person singular and it lacked the nominative subject. The impersonal passive is represented in (7) below.

(7) ... buton him durh his hreowsung \& durh Godes miltse gehopen weorde but him-DAT through his penitence and through God's mercy helped become

'... but he is helped by his penitence and by God's mercy.'

Alfred's Cura Pastoralis 251

Bondaruk and Charzyńska-Wójcik (2003: 347)

As illustrated in (7) in the impersonal passive the dative object occurring sentence initially remains unaffected by fronting- the dative does not change into the nominative. However, this type of structure was not attested with accusative objects, as discussed in detail in Bondaruk and Charzyńska-Wójcik (2003: 345-349). Another way of expressing the passive in Old English was the direct passive, where the accusative DO in the active becomes the nominative subject in the passive. Compare the example in (8), taken from Bondaruk and Charzyńska-Wójcik (2003: 344):

(8) pu eart on eallum pingum wel gelæred.
you are in all things well taught
'... you are well instructed in all things.'

Apollonius of Tyre 26

The most obvious difference between the instances of the impersonal passive, as in (7), and the direct passive, as in (8), except for the case of nominal phrases, is the verbal concord- now the verb agrees with the nominative subject which is marked for the second person singular.

The impersonal and the direct passive were the most common ways of expressing the passive in OE, as the indirect passive was not acceptable. The indirect passive is a construction 
where the dative object becomes the subject in the passive with a change of case into the nominative. The means of expressing the passive in English began to change, when case syncretism took place- the remaining forms, like e.g. him, could denote either the dative or the accusative. The first instances of the indirect passive emerged as early as early Middle Englishdue to the lack of case distinction on objects, monotransitive verbs with the dative object adopted the case change mechanism of the direct passive- this resulted in the dative becoming the nominative. Later, the pattern affected the ditransitive constructions, as well.

Taking these processes into consideration, Bartczak-Meszyńska (2013) and Bondaruk and Bartczak-Meszyńska (2014) propose that the dative changed into the accusative in English. Apart from the diachronic analysis of English facts, they support this claim with the comparison of English structures with their (Modern) German equivalents. After both the direct and the indirect passive became attested in English, the DOC acquired the properties characteristic for the double accusative DOC in German and became subject to the same transformations as its German counterpart. Since both objects can become subjects in the passive, their case has to be structural (the dative is inherent ${ }^{11}$ ). Moreover, the properties of the dative objects in Old English exhibit striking parallels to the properties of the dative objects in (Modern) German. The dative object can appear sentence initially but it does not change in the passive; structures like the impersonal passive in Old English are still attested in German, which is illustrated in (9).

(9) Ihr kann von ihr Mutter geholfen werden.

she $_{\text {DAT }}$ can by her mother helped be

'She can be helped by her mother.'

Taking the discussion above into consideration and assuming that the case of both objects is accusative, we suggest the structure in (10), which illustrates the case valuation mechanism in the English DOC.

(10)

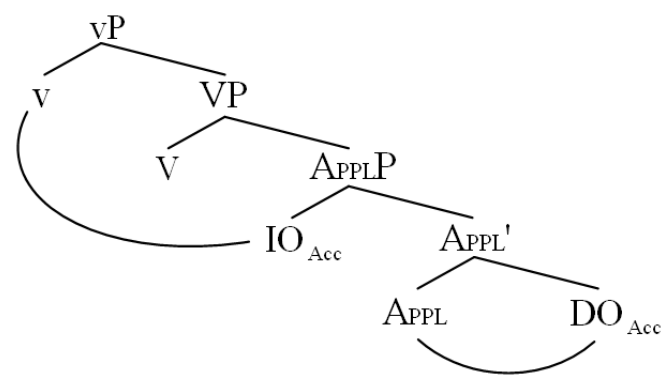

Since we proposed that both objects bear the accusative case, we need to have two Probes to value the two occurrences of structural case. Following Citko (2011), it is assumed that v is one source of case in this type of structure, the other is the Applicative head. Consequently, the Applicative in English is not entirely typical, since it does not value the dative but structural accusative, exactly like the Applicative in the German double accusative DOC. This

\footnotetext{
${ }^{11}$ Our observation is valid for the languages discussed, but the properties of the dative case may differ crosslinguistically.
} 
proposal differs from traditional proposals in yet another way: $\mathrm{v}$ values the case of the IO and the DO has its case valued by the Applicative.

Such an approach accounts for the existence of symmetric passive ${ }^{12}$ in English: passive morphology absorbs the ability to value accusative either on $\mathrm{v}$ or on the Applicative. The object of the Probe affected by the passive morphology with an unvalued case is then forced to become a subject and enter Agree with T, which values its case as the nominative.

\subsection{The syntactic structure of the PC in English}

The tree diagram in (11) below represents the 'standard' syntactic structure of the PC in English. ${ }^{13}$

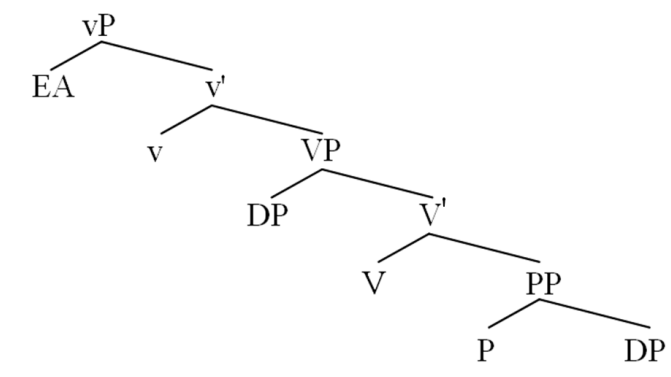

Since in this structure there is only one 'free' DP (not embedded in the PP), the DO, its case has to be valued as the accusative by the phase head $\mathrm{v}$. The structure in (11) does not contain the Applicative Phrase but its absence does not entail that the case of the second object (either a DP or a pronoun) remains unvalued- its case is valued by the Preposition in the PP.

\section{Object fronting out of the DOC and the PC in English}

\subsection{Object fronting in the active}

As has already been mentioned, either object can occur in the sentence initial position. Since such sentences are stylistically marked and the resulting word order visibly influences the meaning of the utterance, we assume that the process responsible for the object displacement must be connected with Information Structure. ${ }^{14}$ Since object fronting represents the emphasis on an element already known to the speaker, so called 'old information', we assume

12 The term symmetric passive has been used in the literature to denote the ability of either direct or indirect object to become a subject of a passive sentence.

${ }^{13}$ Similar representations were proposed in e.g. Larson (1988) or Jackendoff (1990) although instead of $\mathrm{v}$, they propose an additional projection of $\mathrm{V}$, which functions in the same manner as $\mathrm{v}$ - the subject merges in its Specifier position.

14 The term 'Information Structure' is described by Chafe (1976) as a packaging of information conveyed in an utterance. Krifka and Fery (2008) provide additional characteristics of this 'packaging': they define Information Structure as the techniques that optimize the form of the message with the goal that it be well understood by the addressee in the current attentional state. Information Structure contains categories such as: Focus, Topic and Givenness. 
that it instantiates Topicalization. ${ }^{15}$ Let us now have a look at how the derivation of sentences with a fronted object proceeds. The sentence in (12) exemplifies the Topicalization of the IO.

a. Her/The girl, Bob gave the pen. ${ }^{16}$

b.

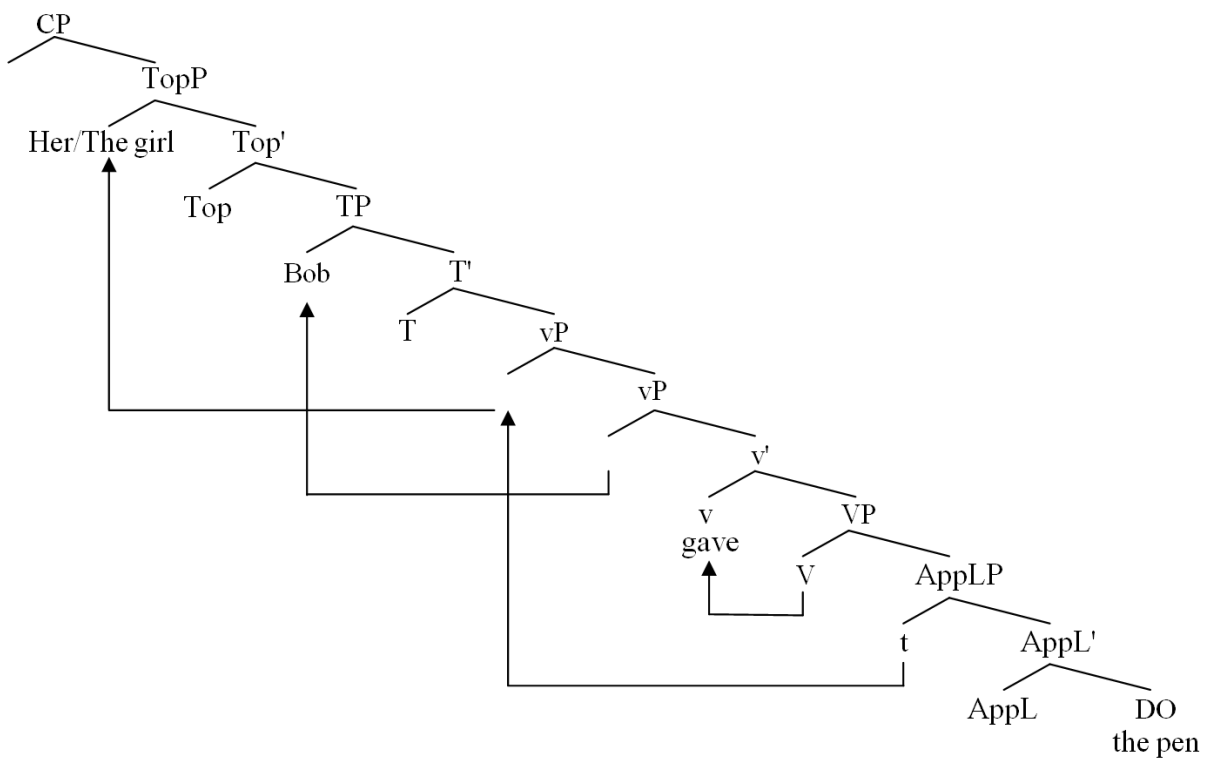

The derivation begins with the merger of the DO with the Applicative (the Applicative values the accusative case on the DO), which is followed by the merger of the IO in the Specifier position of the Applicative Phrase (ApplP). The VP merges with the ApplP, as a part of the vP phase. The External Argument (EA, the subject) is in the Specifier, vP position. The phase head $\mathrm{v}$ values the accusative on the IO. The object undergoing fronting has to possess an unvalued feature Topic (uTop), which allows for its further movement (according to minimalist assumptions, all processes have to be syntactically justified, they involve feature checking and happen to prevent the derivation from crashing). In (12) the topicalized object is the girl/her, which moves to the Specifer of the phase head, the $\mathrm{vP}$, is attracted by the Edge Feature (EF) of v. The case of the subject has to be valued, therefore, the EA enters the operation Agree with T, which values its case as the nominative. The subject moves to the Specifier, TP to satisfy the EPP feature on T. The verb moves to v. After the merge of the next phase $\mathrm{CP}^{17}$, containing the Topic Phrase (TopP), the TopP values the uTop feature on the object in the Spec, vP and attracts it to its Specifier position, thanks to the EF of the TopP.

The derivation of a sentence with a topicalised DO occurs in a similar way, as illustrated in (13).

${ }^{15}$ The issue of Topicalization in English is not as straightforward as we characterise it here. A detailed analysis of this phenomenon and evidence supporting our claim is offered by e.g. Erteschik- Shir (2006), Prince (1981), Speyer (2010), Tajsner $(1998,2008)$.

${ }^{16}$ The pronouns are used as an addition to DPs to signal the changes of the case marking.

${ }^{17}$ In our representations we utilise Rizzi's $(1997,2004)$ Split-CP proposal and his version of the Relativised Minimality. 
(13) a. The pen, Bob gave her/the girl.

b.

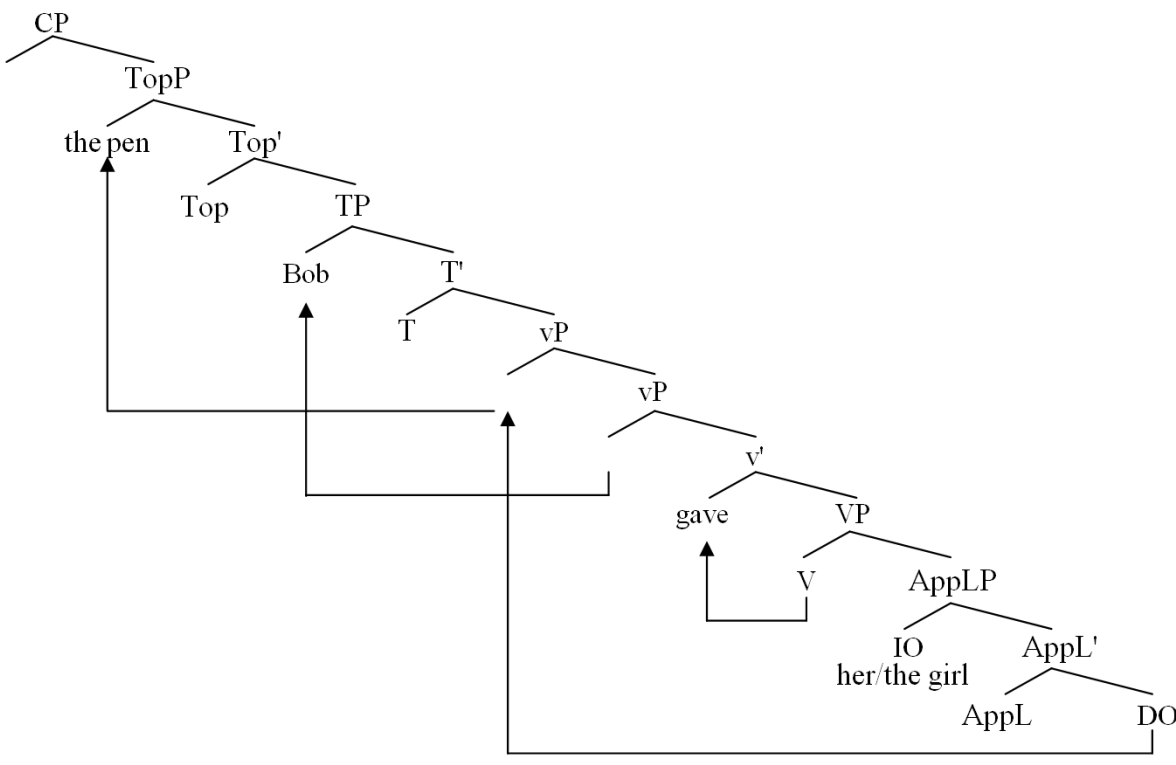

Here, as in the derivation above, the Applicative merges with the DO, values its case as the accusative, the IO is merged in the Specifier of the Applicative phrase. The VP merges with the Applicative, the EA merges in the Specifier, vP position. The phase head values the accusative on the IO. The EA enters Agree with T and moves to Spec, TP. This time it is the DO with the uTop which moves to the Specifier of the phase head. After the merge of the TopP into the structure, the TopP values the uTop of the DO and the DO moves to the Specifier, TopP, attracted by its EF.

In the ditransitive constructions with the $\mathrm{PD}$, it is also possible to displace either the nominal DO or the PP object. The example in (14) illustrates the fronting of the DO, while the $\mathrm{PP}$ remains in its original position.

(14) a. The pen, Bob gave to the girl/her.

b.

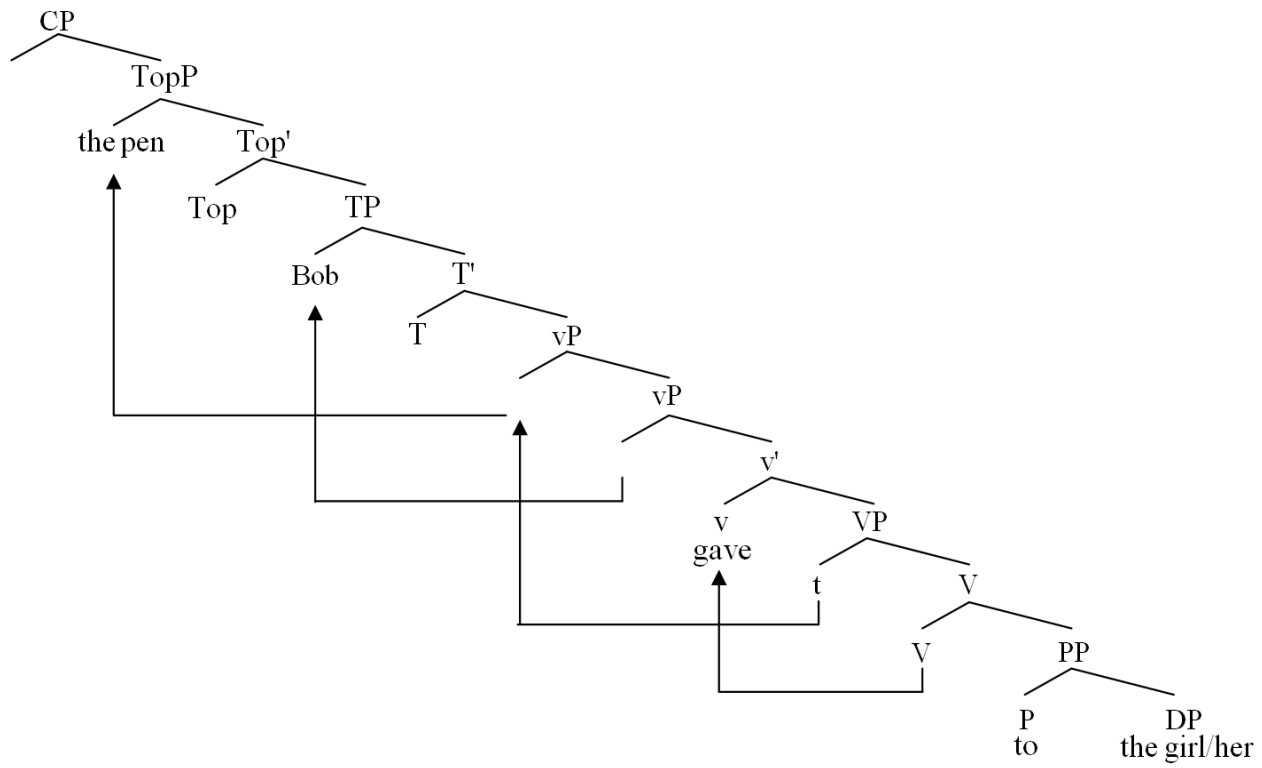


The derivation of the sentence in (14) occurs in the following manner: the nominal expression merges with the preposition, which values its case. The PP merges with the VP, with the DO in its Specifier position. The phase head v values the case of the DO as the accusative. The DO still possesses the unvalued feature uTop and moves to the Specifier, vP, triggered by the EF of the phase head. The subject Bob enters Agree with T, which values its case as the nominative and attracts the EA to Spec, TP to satisfy the EPP feature on T. As the TopP merges into the structure it values the uTop on the DO and triggers its movement to Spec, TopP thanks to its EF.

When the PP object gets topicalized it also has to have a uTop, which is presented in (15).

(15) a. To the girl/ to her, Bob gave the pen.

b.

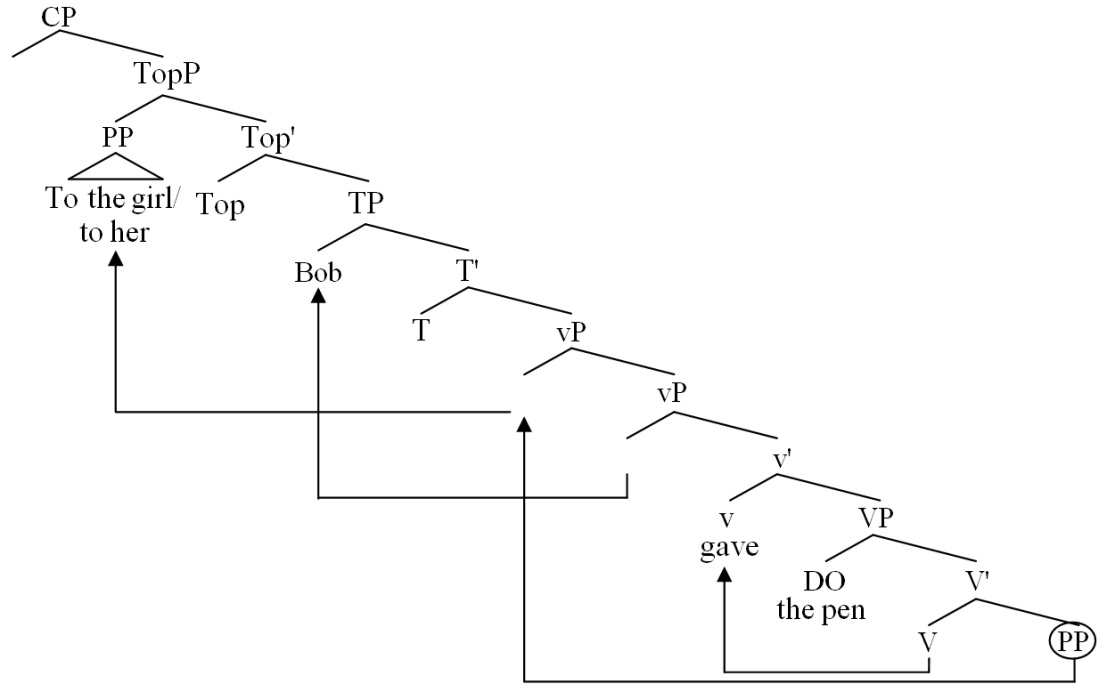

In (15), $\mathrm{P}$ to merges with a DP, values its case and together they constitute a PP. This PP merges with the VP, the DO merges into the structure in the Specifier, VP position, the phase head $v$ values the accusative case on the DO. The EA merges in the Specifier of vP. The PP object with an uTop is attracted by the EF of vP and moves to the Specifier position of the phase head. The EA has its case valued as the nominative by $\mathrm{T}$ and moves to Spec, TP to satisfy the EPP feature of T. When the TopP merges with the TP, it values the uTop of the PP object and attracts it to the Spec, TopP. The verb moves to v.

The derivation characterised above, when the object moves together with the $\mathrm{P}$, exemplifies the process called Pied-Piping. However, in English the DP object can move out of the PP and become topicalized on its own, leaving the preposition in it first merge position, which is called P-Stranding ${ }^{18}$.

In English, both Pied-Piping and P-Stranding are acceptable. The sentence in (15) above is an instance of Pied-Piping. The process of P-Stranding is illustrated in (16).

18 Whereas the process of Pied-Piping seems to be common cross-linguistically, P-Stranding does not occur as freely. Several accounts of this phenomenon have been proposed, e.g. van Riemsdijk (1978), Hornstein and Weinberg (1981), a more recent explanation utilizing the theory of phases has been put forward by Abels (2003). 
(16) a. The girl/her, Bob gave the pen to.

b.

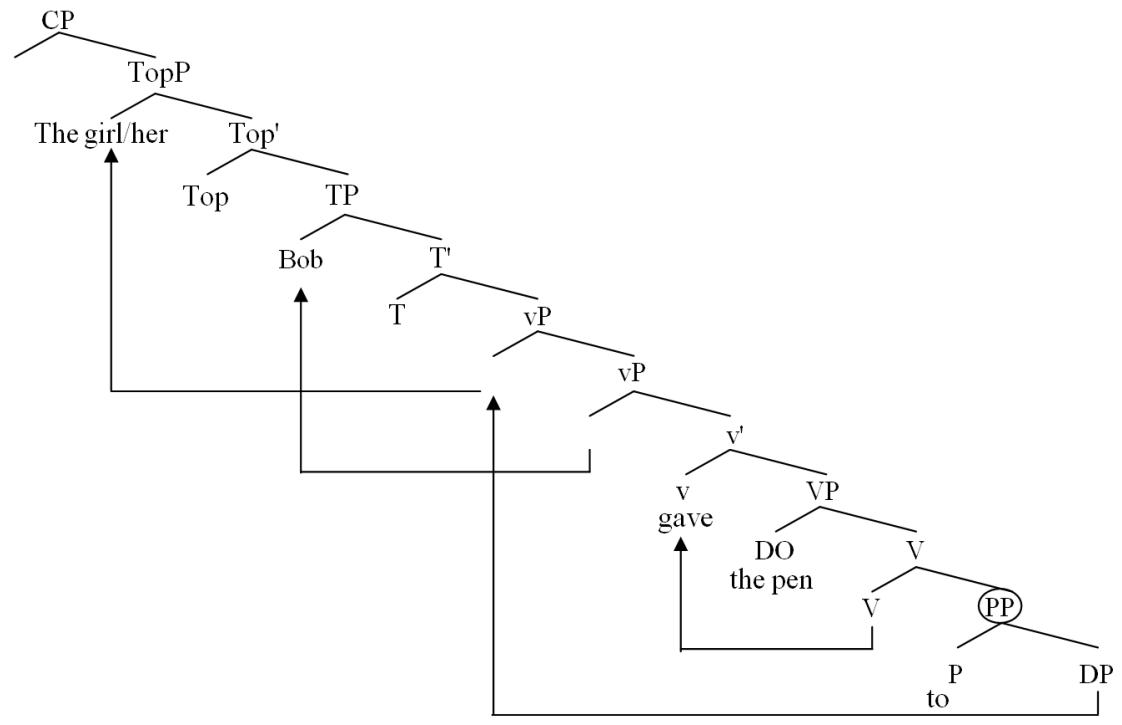

How does this derivation differ from the one in (15) above? The whole PP is not subject to topicalisation, only the DP complement of PP possesses un unvalued feature Top. Hence, in the final stage of the derivation it is the DP alone that moves to the Specifier, Top and the preposition remain in its first merge position.

\subsection{Object fronting in the passive}

In the passive, object fronting can be caused by two processes: when only one object is fronted, it usually represents Passivisation. If both objects move, one instantiates Passivisation, the other Topicalization. Let us start with the process of passivisation, which is the focus of the next section.

\subsubsection{Passivization}

The sentence in (17) illustrates the direct passive - the DO in the active becomes the subject in the passive, which is accompanied by the change of its case in the nominative.

(17) a. The pen was given the girl/her. (the DO passivised)

b.

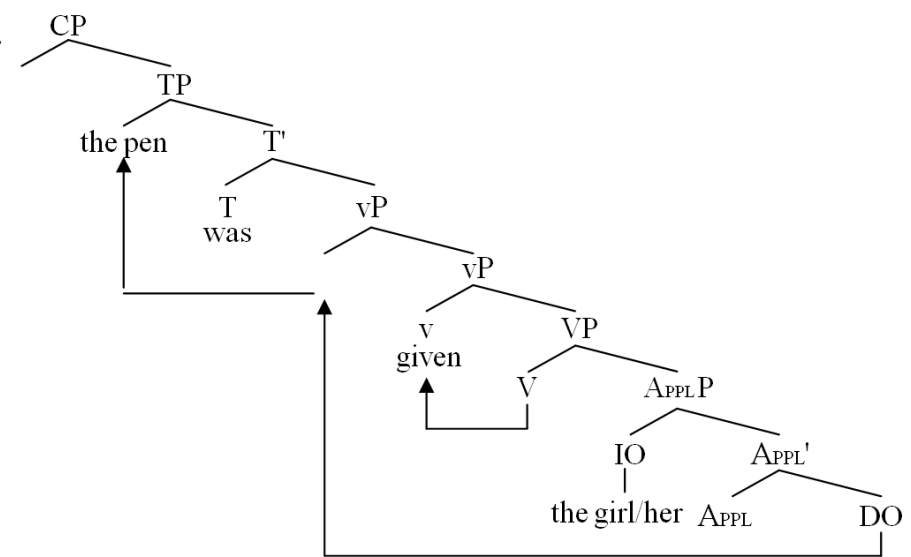


In (17) the derivation proceeds in the following manner. The Applicative merges with the DO, the IO is merged in its Specifier position. v values the case of the IO as the accusative. The passive morphology absorbs the ability of the Applicative to value case and the DO has to seek another Probe to have its unvalued case feature valued, in order to prevent the derivation from crashing. The relevant Probe to value the case of the $\mathrm{DO}$ as the nominative is $\mathrm{T}$. However, the IO is closer to $\mathrm{T}$ than the DO and it would induce the Defective Intervention Effect and thus block Agree between T and the DO. Consequently, to enter Agree with T, the DO needs to move to a position c-commanding the IO. Following Bondaruk and BartczakMeszyńska (2014), we assume that this position is Specifier, vP. They propose that the movement of the DO is triggered by the Edge Feature (EF) of v, which has not been affected by the passive morphology. Since $v$ values the accusative on the IO, it can still be considered a phase head and as such possesses the EF. Now the DO is closer to T than the IO, T values the case of the DO as the nominative and attracts it to its Specifier position to satisfy the EPP feature on $\mathrm{T}$.

There are some issues in the derivation outlined above that need further elaboration. First, although $\mathrm{v}$ is in the passive, it is still perceived as a phase head. Bondaruk and BartczakMeszyńska (2014), following Chomsky $(2000,2001)$ claim that if $v$ has not lost its ability to value the accusative (although it lacks the EA), it is transitive and transitive v constitutes a phase head. Secondly, the DO is attracted to Specifier, vP, although v does not value its case. In order to provide a solution to this problem, Bondaruk and Bartczak-Meszyńska (2014) assume that v enters Agree with both the IO and the DO (multiple Agree, cf. Hiraiwa (2002)). As the IO is closer to the phase head, it values the $\varphi$-features on $\mathrm{v}$ and $\mathrm{v}$ values the case on the IO as the accusative. The syntactically active DO with an unvalued case moves to the Specifier of the phase head to satisfy its EF and is available to another Probe. Any other scenario would leave the case feature of the DO unvalued and cause the derivation to crash.

Let us now turn to the indirect passive.

a. The girl/She was given the pen. (the IO passivised)

b.

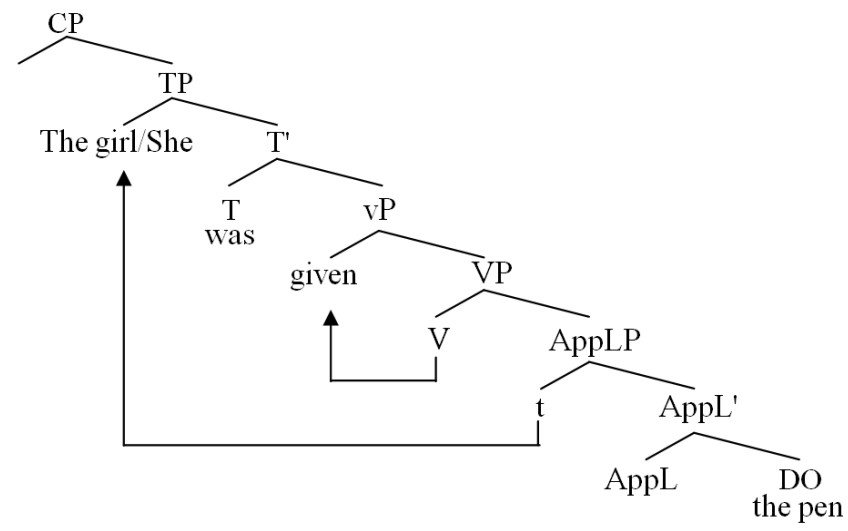

The derivation of the indirect passive is less complicated than the derivation in (17) above. The DO merges with the Applicative, which this time is not affected by the passive morphology and values the case on the DO as the accusative. The IO merges in the Spec, ApplP and the Applicative Phrase merges with the phase $\mathrm{vP}$, whose case valuation ability has been rendered inactive by the passive morphology. Since the IO is merged above the DO, the 
DO cannot interfere in the syntactic operations between the IO and the projections in the next phase. After T enters the derivation, it values the case of the IO as the nominative and attracts the IO to its Specifier position to have its EPP feature satisfied.

The derivation of the passive sentence with the PC is even more straightforward because there is only one object that can enter Agree with $\mathrm{T}$ and become subject of the passive sentence.

(19) a. The pen was given to the girl/her.

b.

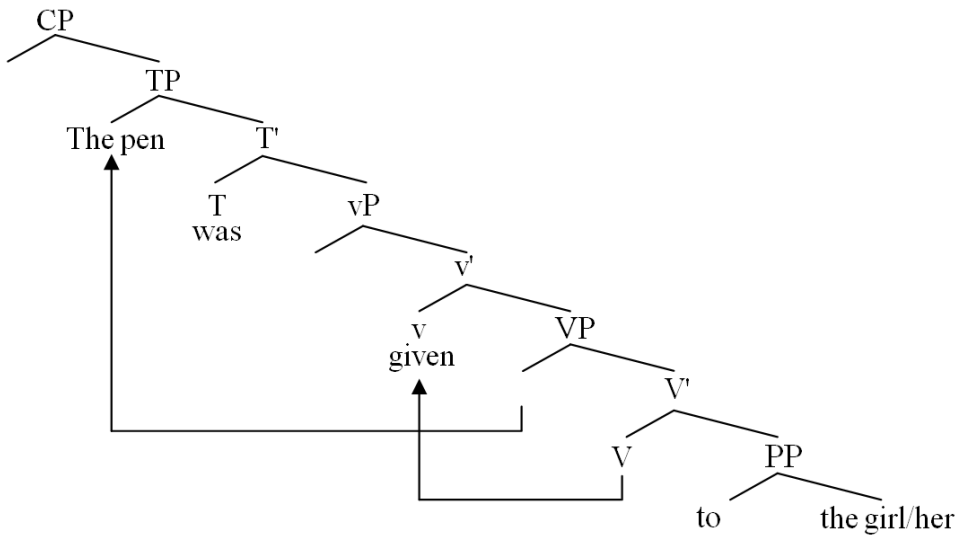

The nominal expression (DP the girl or the pronoun her) merges with the PP, which values its case. The PP merges with VP, the DO merges in the Specifier, VP. The vP enters the derivation but cannot value the case of the DO, due to the fact that the passive morphology absorbs its case marking ability. The TP merges with $\mathrm{vP}$ and values the case of the DO as the nominative, which moves to Spec, TP to satisfy the EPP on T. This is the only acceptable derivation with the PC, because the PP cannot enter Agree with T and satisfy the EPP feature of $\mathrm{T}$, as illustrated in (20).

(20) a. ${ }^{*}$ To the girl/her was given the pen.

b.

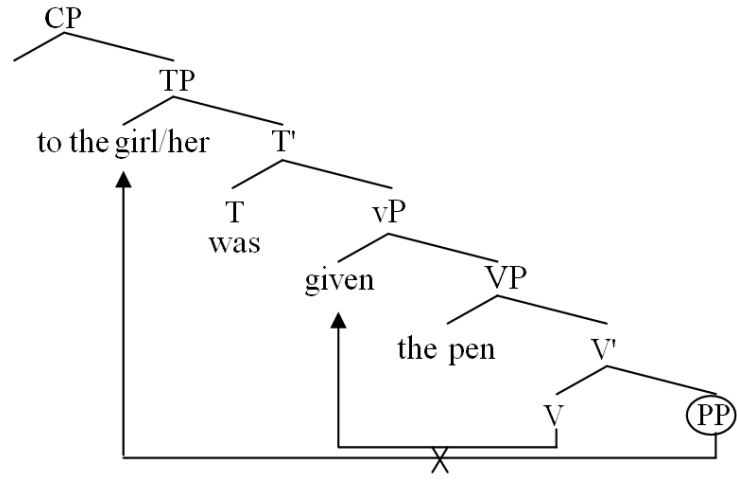

\subsubsection{Topicalization}

When in the passive both objects leave their first merge position, their displacement instantiates distinct processes: one of the objects gets fronted by Passivisation, the fronting of the other is triggered by Topicalization. The choice depends on the passive morphology, the 
passive morphology absorbs the case valuing abilities of one of the Probes. The Goal of the Probe affected by the passive morphology must look for another Probe to have its case valued$\mathrm{T}$ is the available Probe to value case, so the Goal enters Agree with $\mathrm{T}$ and becomes a subject in the passive. The movement of the other object, whose case feature is valued in-situ, exemplifies Topicalisation.

Let us now analyse object movement in greater detail.

a. The girl/Her, the pen was given.

b.

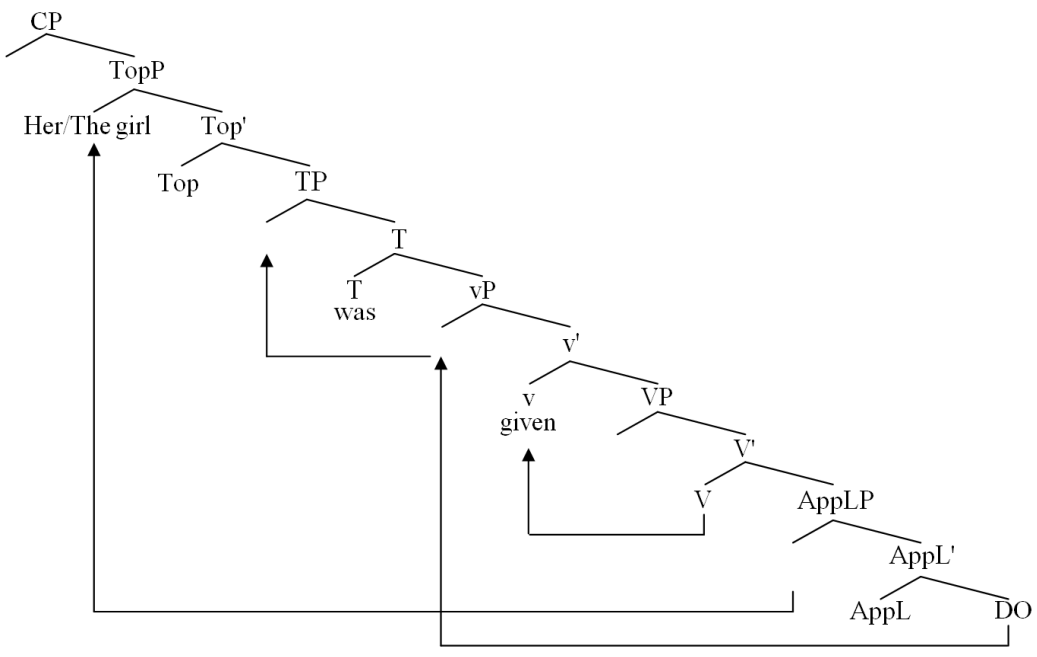

In (21) above the DO undergoes passivisation and the IO becomes the Topic. The derivation proceeds in the following manner: the Applicative merges with the DO, the IO merges in the Specifier of the Applicative position. Whereas the phase head values that case of the IO as the accusative, the Applicative is rendered inactive by the passive morphology and cannot value the case of the DO. The DO moves to the Specifier of $\mathrm{vP}$, as in (17b) above. The DO enters Agree with T, which values its case as the nominative. The IO is still active- it has its case feature valued in the first merge position but its uTop feature remains unvalued. After the DO enters Agree with T, it moves to Specifier, TP, to satisfy the EPP on T. The TopP merges with the TP, TopP values the uTop on the IO and its EF feature induces the fronting of the object attracting it to Specifier, TopP.

(22) a. The pen, the girl/she was given.

b.

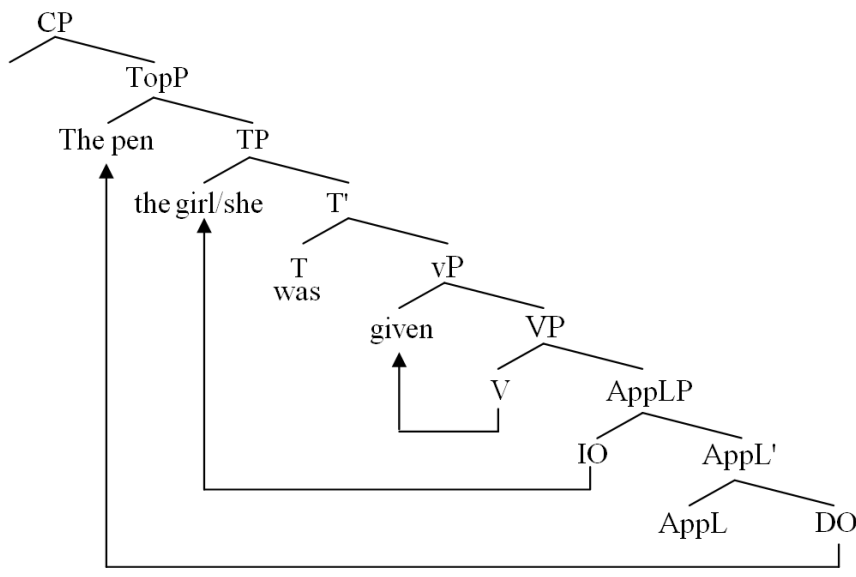


In the derivation represented in (22), it is the DO that has an uTop feature and the IO becomes the subject. The DO merges with the Applicative, which values its case as the accusative, its uTop feature remains unvalued. The IO merges in the Spec, ApplP and the Applicative Phrase merges with the $\mathrm{vP}$ which is affected by the passive morphology and cannot value the case of the IO. The IO enters Agree with $\mathrm{T}$ which values its case as the nominative and it moves to Spec, TP to satisfy the EPP on T. As the TopP enters the derivation, it checks the uTop on the DO and attracts the DO to Spec, TopP.

Now let us consider object fronting in the ditransitive constructions with the PC. The examples in both (23) and (24) contain a DO realised by a DP and the pronoun. However, they represent different processes. In (23) below, it instantiates Pied-Piping, since the PP moves together with its complement. On the other hand, in (24) the P remains in its first merge position, hence the sentence in (24) represents P-Stranding.

(23) a. To the girl/her, the pen was given.

b.

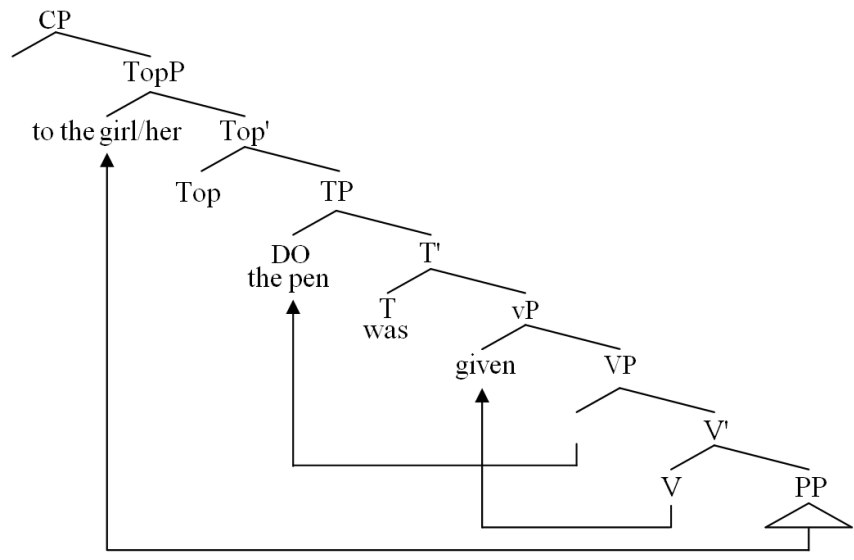

In (23) above the derivation happens in the following manner: a DP/pronoun merges with the preposition, which values its case. The whole PP has to possess the feature uTop. Then the VP enters the derivation with the DO in its Specifier position. The DO seeks a Probe to have its case valued, even after the vP merges into the structure, since the ability of the phase head $\mathrm{v}$ to value case has been rendered inactive by the passive morphology. It undergoes Agree with $\mathrm{T}$ and moves to Spec, TP to satisfy the EPP feature on T. As soon as the TopP enters the derivation, it values the uTop of the PP and attracts it to Spec, TopP.

(24) a. The girl/her, the pen was given to.

b.

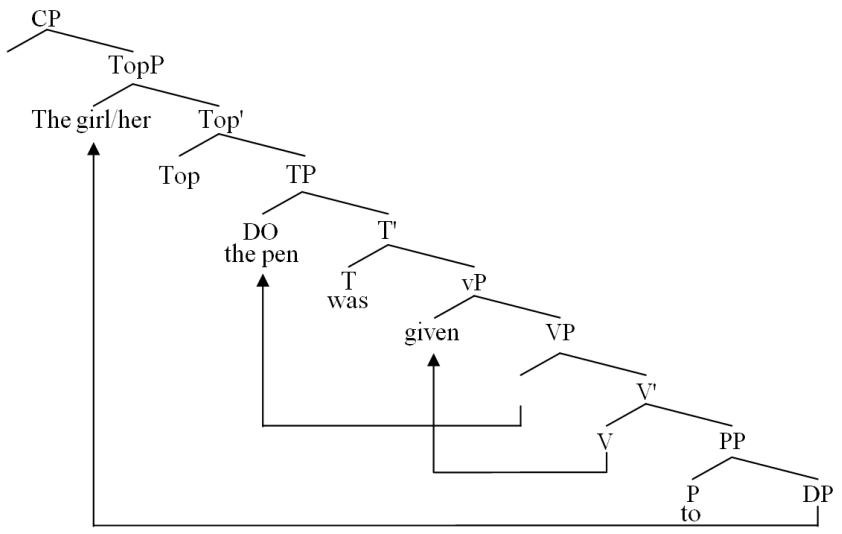


Since the sentence in (24) allows P-Stranding, it must be only the DP complement of the PP which has the uTop. The derivation proceeds in the way similar to the derivation in (23). The preposition values the case of its complement but it cannot value its Top feature. The VP merges into the structure with the DO in its Specifier position. The VP merges with $\mathrm{v}$ which is unable to value the case on the DO, hence the DO undergoes Agree with $\mathrm{T}$, has its case valued by $\mathrm{T}$ as the nominative and moves to Spec, TP to satisfy the EPP feature on T. When TopP merges with the TP, it values the uTop on the complement of the PP and attracts it to Spec, TopP by its EF.

\section{Conclusions}

The aim of this paper has been to analyse the patterns of displacement the objects in the English DOC can undergo. Our study involved not only objects realised by nominal expressions, like DPs and pronouns but also the PP object in the Prepositional Construction. We considered here all the possible types of the ditransitive constructions, although not all of them, such as the DO-IO DOC, are perceived as acceptable by all the native speakers of English.

First, we established the basic underlying representation of both the DOC and the PC, applying Citko's (2011) structure with the Low Applicative to English. Secondly, in order to investigate the case valuation mechanism in the English DOC, we decided, that since either object can become the subject in the passive, its case has to be structural. Taking the diachronic properties of the English case system and its comparison with German, we assumed that the case on both objects has to be valued as the accusative.

The remainder of this paper has been devoted to the analysis of the displacement either one object or two objects can undergo simultaneously to the front of the sentence. It has been concluded that in the active, when the object moves to the sentence initial position (in such cases only one object can move in the front of the subject), its dislocation has to be an instance of Topicalization. As sentences beginning with an object are extremely stylistically marked, and are used only in particular discourse situations, their derivation must reflect Information Structure.

In the passive, if an object moves forward, it becomes the subject of the passive sentencethis process is called Passivisation. If both objects move simultaneously, their movements must be induced by different factors: one undergoes Passivisation, the other, at the left edge of a sentence, is topicalized. The choice of the exact process the objects are subject to depends on the passive morphology- the object whose Probe is affected by the passive morphology has to have its case valued as the nominative by $\mathrm{T}$, hence undergoes Passivisation. If the other object moves, this is caused by reasons related to Information Structure.

\section{References}

Abels, K. 2003. Successive-cyclic, anti-locality and adposition stranding, Ph.D. diss., Storrs, University of Connecticut. Anagnostopoulou, E. 2003. The syntax of ditransitives. Evidence from clitics. Studies in Generative Grammar 54. Berlin/New York: Mouton de Gruyter. 
Bartczak-Meszyńska. A. 2013. The double object construction in English and German. Structural position, case valuation and movement of objects. Ph.D. diss., Lublin, John Paul II Catholic University of Lublin.

Biggs, A. 2014. Dissociating Case from Theta-roles: A comparative investigation. Ph.D. diss., King's College, University of Cambridge.

Biggs, A. 2015. A new Case for A-movement in Northwest British English. In U. Steindl, T. Borer, H. Fang, A. Garcia Pardo, P. Guekguezian, B. Hsu, Ch. O'Hara, and I. Chuoying Ouyang (eds.), Proceedings of the 32nd West Coast Conference on Formal Linguistics (WCCFL 32), 218-227. Somerville: Cascadilla Proceedings Project.

Bondaruk, A., and M. Charzyńska-Wójcik. 2003. Expletive pro in impersonal passives in Irish, Polish and Old English. Linguistische Berichte 195: 325-362.

Bondaruk, A., and A. Bartczak-Meszyńska. 2014. Dative or accusative in disguise? The study of the Double Object Construction in English. In M. Charzyńska-Wójcik, J. Wójcik and A. Bloch-Rozmej, (eds.), Language change, faces and facets. Studies in Linguistic and Methodology 7. 25-42. Lublin: Wydawnictwo KUL.

Boneh, N., and L. Nash. 2011. When the benefit is on the fringe. In J. Berns, H. Jacobs, and T. Scheer (eds.), Romance languages and linguistic theory XX, 19-38. Amsterdam: John Benjamins.

Bresnan, J. 2007. Is syntactic knowledge probabilistic? Experiments with the English dative alternation. In S. Featherston, and W. Sternefeld (eds.), Studies in Generative Grammar. Roots: Linguistics in search of its evidential base, 77-96. Berlin: Mouton de Gruyter.

Bresnan, J., A. Cueni, T. Nikitina, and H. Baayen. 2007. Predicting the dative alternation. In G. Boume, I. Kraemer, and J. Zwarts (eds.), Cognitive foundations of interpretation, 69-94. Amsterdam: Royal Netherlands Academy of Science.

Bresnan, J., and T. Nikitina. 2009. The gradience of the dative alternation. In L. Uyechi, and L.-H. Wee (eds.), Reality Exploration and discovery: Pattern interaction in language and life, 161-184. Stanford: CSLI Publications.

Bruening, B. 2010a. Double Object Constructions disguised as prepositional datives. Linguistic Inquiry 41: 287305.

Bruening, B. 2010b. Ditransitive asymmetries and a theory of idiom formation. Linguistic Inquiry 41: 519-562.

Chafe, W. 1976. Givenness, contrastiveness, definiteness, subjects, topics and point of view. In C. Li, Subject and topic, 27-55. New York: Academic Press.

Chomsky, N. 2000. Minimalist Inquires: The framework. In R. Martin, D. Michaels, and J. Uriagereka (eds.), Step by Step, 89-155. Cambridge, MA: MIT Press.

Chomsky, N. 2001. Derivation by phase. In M. Kenstowicz (ed.), Ken Hale. A life in language, 1-52. Cambridge, MA: MIT Press.

Chomsky, N. 2007. Approaching UG from below. In U. Sauerland, and H.-M. Gartner (eds.), Interfaces + Recursion = Language?: Chomsky's minimalism and the view from syntax-semantics, 1-29. Berlin/New York: Mouton de Gruyter.

Chomsky, N. 2008. On phases. In R. Freidin, C. Otero, and M.-L. Zubizaretta (eds.), Foundational issues in linguistic theory. Essays in honour of Jean-Roger Vergnaud, 134-166. Cambridge, MA: MIT Press.

Citko, B. 2011. Symmetry in syntax. Merge, Move and labels. Cambridge: Cambridge University Press.

Cuervo, M. 2003. Dative at large. Ph.D. diss., Cambridge, MA, MIT.

Emonds, J. 1973. Evidence that indirect object movement is a structure-preserving rule. In. M. Gross, M. Halle, and C. Schutzenberger (eds.), The formal analysis of natural languages, 63-70. The Hague: Mouton.

Erteschik-Shir, N. 2006. On the architecture of Topic and Focus. In V. Molnar, and S. Winkler (eds.), The architecture of focus. Studies in Generative Grammar 82, 33-57. Berlin: Mouton de Gruyter.

Grashchenkov, P., and V. Markman. 2008. Non-core arguments in verbal and nominal predication: High and Low Applicatives and possessor raising. In N. Abner, and J. Bishop (eds.), Proceedings of the 27th West Coast Conference on Formal Linguistics (WCCFL 27), 185-193. Somerville: Cascadilla Proceedings Project.

Haddican, W. 2010. Theme-goal ditransitives and theme passives in British English dialects. Lingua 120: 24242443. 
Haddican, W., and A. Holmberg. 2011. Object movement symmetries in British English dialects: Experimental evidence for a case-based approach. In C. Jaehoon, E. Hogue, J.Punske, D. Tat, J. Schertz, and A. Trueman (eds.), Proceedings of the 28th West Coast Conference on Formal Linguistics (WCCFL 28), 72-80. Somerville: Cascadilla Proceedings Project.

Harley, H. 2002. Possession and the double object construction. Linguistic Variation Yearbook 2: 29-68.

Hiraiwa, K. 2002. Multiple Agree. Paper presented at GLOW Workshop: tools in linguistic theory, Utrecht Institute of Linguistics.

Hornstein, N., and A. Weinberg. 1981. Case theory and preposition stranding. Linguistic Inquiry 12: 55-91.

Hughes, A., and P. Trudgill. 1979. English accents and dialects: An introduction to the social and regional varieties in the British Isles. London: Arnold.

Jackendoff, R. 1990. On Larson's treatment of the Double Object Constructions. Linguistic Inquiry 21(3): 427456.

Kayne, R. 1994. The antisymmetry of syntax. Cambridge, MA: MIT Press.

Krifka, M., and C. Fery. 2008. Information structure. Notional distinctions, ways of expression. In P. van Sterkenburg (ed.), Unity and diversity of languages, 123-136. Amsterdam: John Benjamins.

Larson, R. 1988. On the Double Object construction. Linguistic Inquiry 19(3): 335-391.

Larson, R. 1990. Double objects revisited: Reply to Jackendoff. Linguistic Inquiry 21(4): 589-632.

Levin, B., and M. Rappaport Hovav. 2007. Deconstructing Thematic Hierarchies. In A. Zaenen, J. Simpson, T. Holloway King, J. Grimshaw, J. Maling, and C. Manning (eds.), Architectures, Rules, and Preferences: Variations on Themes by Joan W. Bresnan, 385-402. Stanford: CSLI.

McFadden, T. 2002. The rise of the to-dative in Middle English. In D. Lightfoot (ed.), Syntactic effects of morphological change, 107-123. Oxford: Oxford University Press.

Oerle, R. 1976. The grammatical status of the English dative alternations. PhD diss., Cambridge MA, MIT.

Pesetsky, D. 1995. Zero syntax. Cambridge, MA: MIT Press.

Prince, E. 1981. Topicalization, focus-movement, and Yiddish-movement: A pragmatic differentiation. Proceedings of the Seventh Annual Meeting of the Berkley Linguistic Society 249-263.

Pylkkänen, L. 2002. Introducing arguments. Cambridge, MA, PhD dissertation, MIT.

Pylkkänen, L. 2008. Introducing arguments. Cambridge, MA: MIT Press.

Rizzi, L. 1997. The fine structure of the left periphery. In L. Haegeman (ed.), Elements of grammar, 281-337. Dordrecht: Kluwer.

Rizzi, L. 2004. Locality and left periphery. In A. Belletti (ed.), Structures and beyond. The cartography of syntactic structures 3, 223- 251. Oxford: Oxford University Press.

Slavkov, N. 2008. Formal consequences of dative clitic-doubling in Bulgarian ditransitives: An applicative analysis. Journal of Slavic Linguistics 16(1): 139-66.

Speyer, A. 2010. Topicalization and stress clash avoidance in the history of English. TiEL 69. Berlin / New York: Mouton de Gruyter.

Tajsner, P. 1998. Minimalism and functional thematization. A cross-linguistic study. Poznań: Motivex.

Tajsner, P. 2008. Aspects of the grammar of focus. A minimalist view. Frankfurt am Main: Peter Lang.

van Riemsdijk, H. 1978. A case studying syntactic markedness: The binding nature of prepositional phrases. Dordrecht: Foris. 